\title{
Research on Inventory Management Based on Gray Forecasting
}

\author{
Zonghan $\mathrm{Li}^{1}$ \\ ${ }^{1}$,North China Electric Power University, No.2Beinong Road,Changping District,China, 102206
}

Keywords: Inventory Management, Gray Forecasting, Gray Model

\begin{abstract}
Gray prediction is mainlydeveloped to study uncertainties of "small samples" and "poor information”. Gray forecastmodel is one of the most important part grey system theory. This paper applies for the gray model prediction to forecastA product demand in every month of 2016. On the basis of the prediction, this paper gives a systematic method to decrease the inventory in S company. The research result of this paper has important implications for improving the inventory management level of S company and other automobile part producers.
\end{abstract}

\section{Introduction}

Inventory, like a double-edged sword, has duple influence on a company. On one hand, it can meet the requirements of customers, prevent the shortage of products and maintain the flexibility of production planning. On the other hand, it occupies the business funds, increases the business costs and hides the business potential problems. Thus, it is very important to hold a moderate amount of inventory to satisfy the reasonable requirements.

Demand forecasting is the basis of the inventory management. However, the pattern of forecasting in S company (an automobile part producer) is very subjective. This thesis in view of this problem uses the gray forecasting method, giving the demand forecasting of A product in $S$ company in every month of 2016 as the gray model is suitable for the mid-long term prediction.

Based on the demand forecasting, we use ABC classification to reduce the workload and raise the work efficiency; we use the JIT pull production mode between the grindery workshop and the assemble workshop to decrease the in-process inventory; we use the KPI method to provide the standard of measuring the work quality of the inventory managers. These systematic methods can help us to resolve the inventory problem of S company.

\section{Establishment of Gray Model}

Firstly, we suppose the road traffic accident data sequence is

$$
x^{(0)}=\left\{x_{1}^{(0)}, x_{2}^{(0)}, \ldots, x_{n}^{(0)}\right\} .
$$

We use the gray system theory to establish the GM $(1,1)$ :

$$
x^{(1)}(t+1)=\left[x^{(1)}(1)-\frac{b}{\mu}\right] e^{-\mu t}+\frac{b}{\mu} .
$$

The expression is the predicted values of the generated sequence. However, what we need is the predictive value of the original sequence. Therefore, it's necessary of accumulated generating operation to achieve the predictive value of the original sequence: 


$$
x^{(0)}=\left\{a^{(1)} x_{1}^{(1)}, a^{(1)}{x_{2}}^{(1)}, \ldots, a^{(1)} x_{n}^{(1)}\right\}
$$

In the above expression,

$$
a^{(1)} x_{1}^{(1)}=x_{t}^{(1)}-x_{t-1}^{(1)}=x_{t}^{(0)}
$$

The test of residual error, that is $E(t)$ :

$$
E(t)=\stackrel{\Delta}{x^{(0)}}(t) \cdot x^{(0)}(t)
$$

The relative residual error is:

$$
e(t)=\frac{E(t)}{x^{(0)}(t)}
$$

The test of posteriori error:

Suppose the mean of the original sequence and the residual errors respectively are

$$
\bar{x}, \bar{E} \text {. }
$$

Suppose the mean square error of the original sequence and the residual errors respectively are

$$
S_{1}^{2}, S_{2}^{2}
$$

Therefore, the ratio of posteriori error is

$$
C=\frac{S_{2}}{S_{1}}
$$

The frequency error is

$$
P=P\left\{\left|E(t)-\bar{E}<0.6745 * S_{1}\right|\right\}
$$

The accuracy of the gray model prediction can be showed in Table 1.

Table 1 Table of the accuracy of valve of $\mathrm{P}$ and $\mathrm{C}$

\begin{tabular}{|c|c|c|}
\hline Level & $\mathrm{P}$ & $\mathrm{C}$ \\
\hline 1 & $>0.95$ & $<0.35$ \\
\hline 2 & $>0.80$ & $<0.45$ \\
\hline 3 & $>0.70$ & $<0.50$ \\
\hline 4 & $<=0.70$ & $<=0.65$ \\
\hline
\end{tabular}

\section{Application of Gray Forecasting in Inventory Management}

Due to the seasonal fluctuation of the demand of A product, we will predict the demand monthly. According to the record of the sales of A product, we achieve the demand of A product in January year by year from 2006 to 2015. The number is as follows. Now, we will use the gray model to forecast the demand in every January in the next 5 years because of the mid-long term quality of gray model.

Table 2 The Demand of A Product in every January from 2006 to 2015

\begin{tabular}{|l|c|c|c|c|c|c|c|c|c|c|}
\hline Year & 2006 & 2007 & 2008 & 2009 & 2010 & 2011 & 2012 & 2013 & 2014 & 2015 \\
\hline Demand & 14 & 12 & 14 & 31 & 38 & 33 & 52 & 59 & 70 & 74 \\
\hline
\end{tabular}


First, the original sequence is:

$\mathrm{x}_{(0)}=[14,12,14,31,38,33,52,59,70,74]$

The generated sequence is:

$x^{(1)}=[14,26,40,71,109,142,194,253,323,397]$

Then, we establish the equation:

$\frac{d x^{(1)}}{d t}+a x^{(1)}=b .(7)$

According to the least square method,

$$
B=\left[\begin{array}{cc}
-0.5\left(x^{(1)}(1)+x^{(1)}(2)\right) & 1 \\
-0.5\left(x^{(1)}(2)+x^{(1)}(3)\right) & 1 \\
\vdots & \vdots \\
-0.5\left(x^{(1)}(n-1)+x^{(1)}(n)\right) & 1
\end{array}\right] .
$$

Then, we use the excel software to get $\mathrm{X}$ and $\mathrm{Y}$.

$$
X=\left[\begin{array}{cc}
-20 & 1 \\
-33 & 1 \\
-55.5 & 1 \\
-90 & 1 \\
-125.5 & 1 \\
-168 & 1 \\
-223.5 & 1 \\
-288 & 1 \\
-360 & 1
\end{array}\right], Y=\left[\begin{array}{c}
12 \\
14 \\
31 \\
38 \\
33 \\
52 \\
59 \\
70 \\
74
\end{array}\right]
$$

So $\mathrm{a}=-0.184, \mathrm{~b}=14.721$ according to the formulas.

$$
\begin{gathered}
\wedge_{(\mathrm{t}+1)}^{(1)}=\left[X_{(1)}^{(0)}-\frac{b}{a}\right] e^{-a t}+\frac{b}{a} \\
\wedge(0) \quad \wedge(1) \quad \wedge(1) \\
X \quad(t+1)=X \quad(t+1)-X_{(t)}
\end{gathered}
$$

The forecasting values of A product in every January from 2016 to 2020 are showed below.

\begin{tabular}{|c|r|}
\hline year & Demand Forecasting \\
\hline 2016 & 99.2 \\
\hline 2017 & 119.2 \\
\hline 2018 & 143.2 \\
\hline 2019 & 172.1 \\
\hline 2020 & 206.9 \\
\hline
\end{tabular}


We can see the get the prediction using the gray model from 2006 to 2015

Table 3 Fitting Effective of Gray Model

\begin{tabular}{|c|r|r|r|}
\hline year & \multicolumn{1}{l|}{ original value } & \multicolumn{1}{l|}{ fitting value } & \multicolumn{1}{l|}{ error } \\
\hline 2006 & 14 & 14 & 0 \\
\hline 2007 & 12 & 19.0 & 7 \\
\hline 2008 & 14 & 22.8 & 8.8 \\
\hline 2009 & 31 & 27.4 & -3.6 \\
\hline 2010 & 38 & 32.9 & -5.1 \\
\hline 2011 & 33 & 39.6 & 6.6 \\
\hline 2012 & 52 & 47.6 & -4.4 \\
\hline 2013 & 59 & 57.2 & -1.8 \\
\hline 2014 & 70 & 68.7 & -1.3 \\
\hline 2015 & 74 & 82.5 & 8.5 \\
\hline
\end{tabular}

Then, we can achieve

$$
\begin{gathered}
C=\frac{S_{2}}{S_{1}}=0.054<0.35 \\
P=P\left\{\left|E(t)-\bar{E}<0.6745 * S_{1}\right|\right\}=1>0.95
\end{gathered}
$$

According to Table 1, the accuracy level is 1.

\section{Inventory Management Based on the Demand Forecasting}

According to Pareto's law, all the materials are made up of "important minors" and "secondary majority". We should distinguish the "important minors" and "secondary majority". In terms of the "important minors", the inventory managers should pay much attention to them. On the other hand, the "secondary majority" only need proper attention. This method can save cost and improve efficiency. This inventory management method is called the ABC classification. The inventory managersof S company can divide all the materials into three classifications and treat different classification differently.

S company adopts the push production mode, leading to the high inventory between the grinder workshop and assembly workshop. S company should take JIT pull mode of production to change the high inventory situation. JIT mode of production is a pulling mode of production. Pulling mode of production is the production mode from back to front. Firstly according to the market demand, the managers determine what to produce and how many to produce. They tell the last process of production the production plan. The production plan advances rapidly step by step. By means of theprinciples of "right time and right amount", the JIT production mode eliminates all the in process inventory.

Due to the lack of performance assessing in S company, the inventory management personnel and inventory operating personnel don't have a responsible attitude toward to their own work. It is one of the most important reasons for the high inventory of S company. We should use the key performance indicators to assess the performance of the employees to reduce the inventory. Specifically, the key performance indicators can be set as the follows: "inventory turnover", “inventory assets ratio” and "inventory accuracy”. 


\section{References}

[1] Lu Yi, The Research and Application of Grey Forecast Model, D., Zhejiang Sci-Tech University, 2014.

[2] Guo Hong, Application of Grey-modelin the Demand Forecast of the Steel Products, D., Shanghai Jiao Tong University, 2007.

[3] Jing Weigang, Dong Jieshuang, FengJipeng, Forecast of the Motor Vehicle Inventory of Middle-sized and Small Cities Based on the Gray Model and It's Application, Logistics Sci-Tech, 8(2015) 40-43.

[4] Han Wentao, Zhang Qian, JiaAnmin, Study on the forecast model of road accident with gray theory, J., Xi'an University of Arch. \& Tech. (Natural Science Edition), 3(2009) 375-377. 